\title{
Estado e mercado: Uma perspetiva institucionalista e relacional
}

State and Market: An Institutionalist and Relational Perspective

État et marché : une perspective institutionnaliste et relationnelle

José Reis

\section{(2) OpenEdition}

\section{Journals}

Edição electrónica

URL: http://journals.openedition.org/rccs/4355

DOI: $10.4000 /$ rccs. 4355

ISSN: 2182-7435

\section{Editora}

Centro de Estudos Sociais da Universidade de Coimbra

\section{Edição impressa}

Data de publição: 1 Dezembro 2011

Paginação: 11-34

ISSN: 0254-1106

\section{Refêrencia eletrónica}

José Reis, « Estado e mercado: Uma perspetiva institucionalista e relacional », Revista Crítica de Ciências Sociais [Online], 95 | 2011, colocado online no dia 01 dezembro 2012, criado a 19 abril 2019. URL : http://journals.openedition.org/rccs/4355 ; DOI : 10.4000/rccs.4355 


\section{JOSÉ REIS}

\section{Estado e mercado: Uma perspetiva institucionalista e relacional}

As relações Estado/mercado carecem de uma visão holista das relações entre as dinâmicas materiais e relacionais da sociedade, por um lado, e entre estas e as dinâmicas institucionais, por outro. Sendo o Estado a-instituição-das-instituições, ele comporta mecanismos essenciais à própria existência de mercados, que não são dados "naturais". Conceber o Estado, o mercado e a sociedade como entidades opostas é, pois, errado. Certeira é a perspetiva institucionalista que, ancorada em Polanyi, propõe uma abordagem política do Estado e do mercado. As economias são, de facto, sistemas institucionais de produção onde, aliás, a espessura material do Estado enquanto organização e administração é relevante. Por isso, a perspetiva institucionalista precisa de ser refinada, para mostrar que o Estado não é só uma entidade político-jurídica. Esta é uma das finalidades centrais deste texto.

Palavras-chave: Estado; economia política; institucionalismo; instituições; mercado; relação Estado-mercado.

É nossa opinião que a vida económica pode ser compreendida muito mais claramente se houver um esforço para analisá-la integralmente.

John Kenneth Galbraith (1967: 23)

\section{Introdução}

$\mathrm{Na}$ Teoria dos sentimentos morais, quando Adam Smith fala das condições em que aprovamos ações de outros, refere-se a capacidades morais do próprio sujeito que dá o consentimento, como a empatia e a solidariedade. Mas aponta também a consonância das ações aprovadas com "regras gerais" e com um "sistema de conduta que tende a promover a felicidade do indivíduo ou da sociedade". E especifica que, nesse caso, estamos perante uma "certa beleza, não muito distinta da que atribuímos a qualquer máquina bem engendrada" (Smith, 1999: 406). 
Pode então dizer-se que na relação que estabelecemos com os outros intervêm tanto as nossas razões subjetivas (chamemos-lhes identidade) como circunstâncias decorrentes de princípios que nos transcendem individualmente (designemo-las alteridade). $\mathrm{O}$ autor de $A$ riqueza das nações, onde muitos encontraram apenas a mecânica fria da divisão do trabalho e os princípios do exercício do egoísmo individual e da simples reação a incentivos, vendo nisso fundamento suficiente para uma sociedade de mercado, é, como seria de prever, mais complexo e mais rico do que alguns dos seus intérpretes.

Esta alusão inicial a um clássico impropriamente capturado pela vulgata liberal não pretende ser um argumento literal para discutirmos os problemas contemporâneos da relação Estado/mercado. ${ }^{1}$ Mas é um argumento para que fixemos alguns dos termos que a discussão sobre a complexidade da via coletiva não pode ignorar. Em especial, serve para relembrar que os mecanismos de ação e de decisão nunca são singulares, sendo mais correto considerar que estamos sempre perante conjuntos plurais e diversos.

É por isso que adotarei a ideia de que há problemas que carecem de uma visão holista, verdadeiramente de uma filosofia da vida coletiva, que sirva de referência para compreendermos e interligarmos processos de natureza diversa, que dificilmente podem ser encarados de forma segmentada. Quando se trata do Estado, nem outra coisa se poderia esperar, visto que estamos perante uma entidade que, na sua matriz mais essencial, é política e que, por isso mesmo, exprime da forma mais global a organização da sociedade e a trajetória que esta seguiu em termos históricos.

De facto, a compreensão da matriz constitutiva do Estado carece de uma narrativa sobre as relações entre as dinâmicas materiais e relacionais da sociedade, por um lado, e entre estas e as dinâmicas institucionais, por outro. E carece de uma visão sobre o sentido da vida coletiva que transcenda a racionalidade individual e a ação de natureza meramente egoísta. Acresce que devemos considerar o Estado como a mais complexa entidade institucional - chamar-lhe-ei a-instituição-das-instituições - e que, como tal, dispõe de uma singular espessura organizacional e de uma forte capacidade de retroação sobre as circunstâncias que lhe deram forma e razão de ser. Assim sendo, encontra-se rapidamente uma relação intrínseca entre Estado e mercado, e não a antinomia que frequentemente nos é sugerida.

Os exercícios de captação da complexidade são epistemológicos, na medida em que dependem do conhecimento e das condições da sua produção. Mas são também ontológicos (ou temáticos), na medida em que refletem sobre a existência, o processo da vida e os processos de organização

\footnotetext{
${ }^{1}$ Este texto baseia-se em grande medida nas ideias que já desenvolvi em Reis (2012).
} 
concretos. Quero aqui sublinhar este último ponto, pois as circunstâncias contemporâneas tornam particularmente intensas as dependências recíprocas entre a discussão epistemológica e a atenção ontológica. A enorme complexidade das interações na sociedade dificulta, de facto, uma visão segmentada da organização social e, por essa razão, acentua as fragilidades das perspetivas que não ultrapassam os redutos parciais.

O que aqui se defende é que as ontologias estatais e mercantis são um reflexo especialmente nítido dessa complexidade e, ao mesmo tempo, intervêm fortemente no seu reforço, dada a densidade de papéis e funções que o Estado cumpre, na sequência da intensa aceleração da história que marcou o século XX.

Embora seja certo que o tema do Estado e do mercado é um entre os muitos que nos podem convidar a uma aproximação que supere as dicotomias, pode argumentar-se que este é um exercício particular porque parte de um obstáculo também particular: a presença no pensamento económico de uma forte influência "separatista" que concebe o Estado, o mercado e a sociedade em geral como entidades opostas. Geralmente, esta visão está muito próxima do que julgo ser um preconceito essencialmente ideológico. Trata-se da perspetiva que concebe o Estado como um "problema" face à sociedade, enquanto vê o mercado como "solução". Como se sabe, tal posição concede à sociedade e ao mercado a condição de espaços privilegiados ou exclusivos de iniciativa, dinâmica e liberdade e atribui ao Estado um papel normalizador ou limitador do espírito criador. Ora, este quadro de pensamento é um poderoso obstáculo a uma conceção relacional do Estado. Por isso, procura-se neste texto discorrer num duplo registo. De maneira esquemática, pode dizer-se que num deles se privilegia a evolução social e, por isso, se dá mais atenção às relações entre a evolução social e económica e a forma, o lugar e o papel do Estado. O outro registo foca-se essencialmente na própria natureza do Estado como instituição, associando essa discussão ao papel que se atribui às instituições enquanto configuradoras das dinâmicas económicas e sociais. Evidentemente que a finalidade essencial é enfatizar a perspetiva relacional que aqui se advoga.

\section{A visão liberal: um lugar demasiado central no pensamento económico}

Parece claro que uma dada conceção do Estado pressupõe uma conceção correspondente, simétrica, dos mercados. E vice-versa. A redução da discussão a uma questão dual é, porventura, o primeiro problema com que nos deparamos, pois um tal binómio não é certamente o que melhor nos habilita para uma análise adequada da complexidade das formas de governação nas sociedades contemporâneas onde, a par do Estado e do mercado, 
encontramos outros mecanismos de coordenação como redes, comunidades, hierarquias empresariais ou associações. Podemos, no entanto, assumir que, para as finalidades deste texto, este é um problema menor.

Vamos, então, partir daquela visão dual para chegarmos à discussão principal e à crítica das perceções separatistas da relação Estado/mercado. É, aliás, nesse contexto que é comum encontrarmos duas posições essenciais sobre o lugar e o papel dos mercados, ambas merecedoras de contestação. A primeira admite que os mercados são moralmente neutros e são, portanto, um dispositivo geral de afetação de recursos cuja eficiência deve ser avaliada circunstancialmente. A segunda posição pressupõe que os mercados são mais do que isso - são um mecanismo social essencial e prioritário, pujante de virtudes que se exprimiram ao longo da história gerando efeitos civilizadores e que, contemporaneamente, fundamentam a autonomia e a liberdade dos indivíduos.

Dada a sua essência quase naturalista, os mercados (tidos, nesta perspetiva redutora, como equivalente da economia) são o lugar próprio das relações despolitizadas. Nesta base, eles definem a economia. O que está para lá deles é já parte da política, que constitui uma esfera separada. No entanto, numa significativa inversão do argumento inicial, passou a fazer-se do mercado o lugar de onde deve emanar tudo, incluindo a política, considerando-se que são as suas "leis" que hão de determinar os comportamentos sociais, incluindo os dos Estados. Por isso, vivemos atualmente um período em que uma fortíssima retórica de persuasão deste tipo, que parece ter atingido o seu grau mais elevado, pretende contaminar todas as opções humanas e promover a ideia de que são as restrições incontornáveis dos mercados que têm de ser respeitadas pelas opções sociais e políticas e pelas formas de organização, tanto individuais como coletivas. E não o inverso.

Ainda assim, o que está na base da mais difundida das visões sobre a relação Estado/mercado na ciência económica dominante é uma noção contratualista que assume as virtudes naturais do mercado e que encara o Estado como uma entidade não natural, resultante de uma estrita delegação de poderes dos cidadãos. Estamos perante a visão liberal. Esta assenta numa teoria do Estado baseada nas noções de direitos de propriedade e de custos de transação. Nesta aceção, o Estado é essencialmente o resultado de um contrato ente legislador e constituintes. Por isso, a constituição há de estar limitada à definição de um quadro de direitos de propriedade e o papel do Estado é garanti-lo com minimização dos custos de transação, ${ }^{2}$ objetivo que os cidadãos, por si, não poderiam assegurar, pois reconhecem a incerteza

\footnotetext{
${ }^{2}$ Isto é, os arranjos sociais, políticos ou regulamentares necessários para atingir os fins pretendidos.
} 
radical que os rodeia enquanto indivíduos. É, pois, o contratualismo que está na base das escolhas institucionais. E este resulta de um cálculo sobre a incerteza e a necessidade de a prevenir. Por isso, os indivíduos estabelecem autorizações constitucionais, isto é, concedem um mandato através do qual as instituições assumem a função de vigilância ou prevenção, em nome de quem não está seguro de controlar a sua situação futura. No início há, portanto, um ato fundador dos cidadãos que decidem delegar autoridade num supremo legislador, tendo como recompensa a liberdade e a segurança (beneficiando das economias de escala que resultam de uma delegação coletiva): uma decisão dos cidadãos, que "abstraem de qualquer atenção para com a sua riqueza pessoal”, como dizia Humboldt em 1792, citado por Furuboton e Richter (2001: 11). O Estado é, assim, o produto de um acordo autoimposto que visa libertar as virtudes do mercado e da sociedade e defender, através de uma estrita contenção da política nos limites do Estado, a condição despolitizada do próprio mercado. A separação das duas esferas estaria, pois, consumada.

Esta visão liberal originária não tardou, no entanto, a ser "revista" por uma outra visão liberal, mais mundana, que passou a tratar a relação Estado/mercado como uma relação entre "bondade" (ou virtude) e "perversidade" (ou maldade). Nesta perspetiva, o Estado, criado de forma purificada através do contrato inicial, rapidamente se tornaria numa entidade apropriada por políticos e burocratas rentistas e egoístas (self-seeking). Ele passou a comportar-se e a ser visto como um espaço intensamente "politizado", e não como o legislador inicial. Segundo este modo de ver, os Estados modernos revelariam, afinal, uma forte propensão para a ilegitimidade e para a ultrapassagem das suas atribuições e do seu papel. Assim sendo, o Estado aparece, simultaneamente, como uma construção de indivíduos - de indivíduos conscientes dos limites que a incerteza lhes atribui - e como um ator autoconsciente dos seus próprios interesses, que tende a reproduzir à revelia de quem o criou. Não é, portanto, um Estado-eunuco nem um decisor bondoso e tolerante aquele que passamos a encontrar nas teorias - é antes um Estado perverso, que os indivíduos criaram para tão rapidamente lhes escapar. A perversidade do Estado é a perversidade dos seus agentes, funcionários e políticos que depressa descobrem que podem ser rent-seekers.

Foram os trabalhos da public choice $e^{3}$ que, partindo do problema básico de saber como é que preferências individuais necessariamente diferentes

\footnotetext{
3 "A origem mais recente da teoria da escolha pública pode situar-se em seis obras, hoje clássicas, escritas por economistas e um cientista político, nos finais da década de cinquenta e década de sessenta" (Pereira, 1997: 420). Apontam-se os trabalhos de Duncan Black (em 1958), James Buchanan e Gordon Tullock (em 1962), Mancur Olson (em 1965), Kenneth Arrow
} 
se reconciliam nas instituições políticas, passaram a concentrar-se na oferta de bens públicos e formulam uma teoria da burocracia, retomando até à exaustão os argumentos da autonomia do Estado, da sua separação da sociedade e das divergências cumulativas entre as preferências estatais e as sociais. O mecanismo desta divergência assenta no facto simples de os funcionários e os políticos transformarem as suas próprias preferências (os seus interesses pessoais pelo poder, que querem autorreproduzir) em políticas, razão pela qual o Estado não é senão o "paralelograma" dos interesses dos seus agentes. Por exemplo, as políticas sociais seriam mecanismos perversos que existem porque asseguram aos burocratas que as gerem a manutenção no lugar e a garantia de status. As suas finalidades próprias contariam pouco. Pode haver uma boa ideia inicial mas ela é rapidamente subvertida e convertida em soluções perversas. A crítica desta noção foi devidamente feita por A. Hirschman (1991), quando dissecou a "retórica da reação". ${ }^{4}$

Um campo mais largo do que o precedente é o da economia constitucional (cf. Reis, 2009: 95-117). Com um denso corpo teórico, ela representa uma visão interessada na política (mais precisamente, nos processos políti$\cos )$, no Estado e no facto de as sociedades se organizarem à volta de uma intrincada e complexa estrutura institucional. Mas os pontos nucleares da economia constitucional são os indivíduos e o seu comportamento totalmente subjetivista. Também aqui o Estado e a política não são entidades ou circunstâncias que tenhamos de compreender de forma coletiva, histórica ou processual. Se o objetivo for interpretar as relações intrincadas entre a complexidade da vida e as formas institucionais, então esse não é um problema sentido pela economia constitucional. A teoria económica das constituições em que ela se baseia deve ser entendida apenas como um procedimento destinado a compreender como as preferências individuais podem ser "amalgamadas" para gerarem resultados coletivos. É, de novo, uma noção contratualista, na busca das "razões das normas", que está em causa. Uma noção construída no ambiente de um cerrado debate simultaneamente contra o keynesianismo, contra o paradigma maximizador e contra a ideia de que há escalas de valor externas, exógenas aos indivíduos, que constituem um padrão social preexistente, perante o qual se avaliem as decisões individuais (uma função social de utilidade, por exemplo). A fé individualista

(em 1951), Anthony Downs (em 1957) e William Riker (em 1962). "Estas obras são geralmente consideradas como as fundadoras de dois programas de investigação que têm estado interligados embora sejam distintos: a teoria da escolha pública (public choice) e a teoria da escolha social (social choice) que se autonomizou seguindo os trabalhos de K. Arrow e Amartya Sen [...], mas que mantém uma estreita relação com a public choice" (ibidem).

${ }^{4}$ Veja-se o comentário de Reis e Nunes (1993). 
da leitura constitucional expressa-se diretamente no pressuposto de que os indivíduos, de facto, escolhem as suas próprias restrições, ${ }^{5}$ "pelo menos até um certo grau e dentro de certos limites".

Um autor de referência neste domínio é J. Buchanan. ${ }^{6}$ Fundador da public choice, consagrou na economia constitucional uma elegante e sofisticada construção do constitucionalismo económico. Aí, as razões filosóficas de base são claramente explicitadas, não deixando meio-termo entre concordar ou discordar, mas também não impedindo a quem as recusa o reconhecimento da elegância da proposta. Mais do que ninguém, Buchanan exprimiu a convicção, tornada doutrina, de que "não se pressupõe apenas a existência do indivíduo autónomo: presume-se também que ele é capaz de escolher entre alternativas de um modo suficientemente ordenado, conduzindo a comportamentos racionais" (Buchanan, 1991: 15).

Contudo, esta perspetiva tornou-se rapidamente numa vulgar economia política do welfare state. ${ }^{7}$ Porque, antes dos desenvolvimentos mais elaborados de uma teoria do Estado, o que encontramos é o argumento de que toda a forma de Estado a que tenha sido conferida qualquer autorização vai, na prática, desrespeitá-la, ultrapassando-a, visto que há uma tendência "natural" para o crescimento natural das instituições que gerem transferências para os cidadãos. Este argumento é sobretudo um preconceito. A convicção de que as instituições são incapazes de respeitar os limites, porque isso vai contra os incentivos da atividade política, são verdadeiras ideias de base do contratualismo quando procura raciocinar sobre a esfera institucional. É que quem executa as políticas de bem-estar são políticos normais, vulgares, cujos interesses autónomos não se compaginam e, pelo contrário, subvertem as intenções de autonomia individual que estão na base das interações que constroem a economia as-an-order (abrindo-se aqui a contradição de, afinal, nem todos os indivíduos serem... verdadeiros indivíduos).

\footnotetext{
${ }^{5}$ Numa outra designação trata-se de "fechar" os sistemas em que se processam os comportamentos (Neves, 2004). Os sistemas são abertos quando se supõe que as restrições que balizam as decisões são dadas externamente, são exógenas.

${ }^{6}$ James M. Buchanan é um economista conservador, criador, ainda nos anos cinquenta, de um movimento universitário agressivamente anti-keynesiano e deliberadamente político, dirigido ao estudo da free society, especialmente conhecido com um dos fundadores da escola da public choice. O Prémio Nobel da Economia que lhe foi atribuído em 1986 representa a consagração por Estocolmo da dimensão académica do neoliberalismo daquela década.

7 A proposta de "desmantelamento" do Estado-Providência proporciona também fortes perplexidades, pois ela ilustra as dimensões mais "agrestes" da teoria, como acontece, quando se afirma a superioridade de uma forma de organização da economia que não trate coletivamente problemas como o das pensões de reforma. A liquidação consistiria num acerto de contas com os contribuintes líquidos e os devedores líquidos da segurança social por forma a reduzir todas as gerações a uma situação igualitária e abandonar a gestão estatal, que por natureza é intertemporal (Buchanan, 1986: 178-185).
} 
Por estas razões, o programa liberal passou rapidamente da ideia de contrato para a necessidade de revisão do próprio contrato inicial, limitando-o. Nisto consiste, como se sabe, as tentativas de minimização e desmantelamento do Estado, sobretudo da sua forma de Estado social empenhado na construção de políticas que densifiquem as relações Estado/sociedade.

\section{Um ponto específico da discussão institucionalista acerca do Estado: a noção de mercado como construção política}

O pressuposto de que o Estado é a sede exclusiva da política enquanto o mercado e a economia são entidades despolitizadas tem sido sujeito a críticas severas. Uma dessas visões críticas e alternativas é a proposta de Chang (2001) de que a abordagem política tem de ser assumida tanto para a análise do Estado como para a do mercado. E há de ser certamente na relação entre ambos que a expressão política é mais expressiva.

Prosseguindo uma trajetória aberta, entre outros, por Karl Polanyi (1957: 140), para quem o caminho "para o mercado livre foi aberto e mantido aberto através de um enorme aumento do intervencionismo organizado centralmente, controlado e contínuo", Chang sugere uma abordagem centrada numa economia política institucionalista capaz de iluminar a complexidade institucional do mercado e, em especial, o facto de os mercados serem, irredutivelmente, construções políticas, em vez de estados naturais ou dados de facto sobre que assenta a vida dos indivíduos e das comunidades. São construções políticas porque os direitos de propriedade e os outros direitos que definem as condições dos participantes no mercado se tornam artefactos estabelecidos através de relações de poder, de formas de legitimação e de consagrações jurídicas, políticas e institucionais sem as quais não existiriam. Eles são, de facto, o resultado de "um exercício altamente político", desde a acumulação primitiva capitalista até às formas de privatização contemporâneas (Chang, 2001: 11).

Essa complexidade institucional demonstra-se ainda pela "diversidade institucional do capitalismo", isto é, pelas várias formas de articulação entre o Estado, o mercado e outras instituições. A ausência de uma regra geral ou de uma normalidade é, em termos históricos, ilustrada pelas várias formas de mediação política que originaram modelos diferenciados, como é o caso, por exemplo, do welfare state bismarckiano, na Alemanha, do Estado industrial francês do pós-guerra, ou dos Estados desenvolvimentistas asiáticos. As propostas liberais para uma despolitização do mercado e da economia são, pois, "no mínimo contraditórias e, no máximo, desonestas" (ibidem). Do mesmo modo, as transições pós-comunistas revelaram bem os limites das visões simplistas acerca do mercado. $\mathrm{Na}$ ausência de um Estado 
estruturado e estruturador, o mercado não funcionou espontaneamente, sendo evidentes as formas perversas de ocupação do espaço de circulação de bens e serviços e de ganhos de direitos de propriedade, traduzidas em violência, corrupções e mercado negro (Chang e Nolan, 1995; Stiglitz, 1999).

É neste sentido que os trabalhos sobre as "variedades de capitalismo", ao insistirem na diferenciação e nas especificidades de determinados modelos de desenvolvimento, sublinham que isso resulta da arquitetura institucional particular que, por exemplo, caracteriza de modo diferente uma economia de "coordenação pelo mercado" e uma "economia de coordenação central" (Hall e Soskice, 2001). De facto, as economias são sistemas institucionais de produção (Hollingsworth e Boyer, 1997). E isso significa que os pilares do funcionamento de cada uma das suas formas concretas (o sistema financeiro, a modalidade prevalecente de governação empresarial, as relações entre empresas, o sistemas de relações industriais, os sistemas de educação e formação, a organização do trabalho, o Estado ou os sistemas de inovação) assumem particularidades que, inclusivamente, se estendem às próprias relações entre elas (Jackson e Deeg, 2006). É por isso, aliás, que se supõe que os caminhos para o desenvolvimento implicam a escolha de instituições apropriadas (Rodrik, 2008) - o que pode significar, num primeiro momento, combinações acertadas de Estado e de mercado, ou, em termos mais rigorosos, configurações institucionais progressivamente densas que revigorem a economia e a sociedade e constituam mesmo formas de "refração" das forças que apontam para simples diluições na economia mundial.

As instituições que constituem e rodeiam o mercado são, pois, muito variadas e de diversa natureza. São instituições formais, como o direito ou a regulação estatal, ou instituições informais, como as convenções sociais ou as práticas culturais, ou mesmo regras autoassumidas, como as que incumbem a associações ou redes. Por isso, as limitações (ou mesmo distorções) da visão liberal só podem ser superadas através do abandono do seu "pressuposto mais crucial", que é o pressuposto da autossuficiência individualista, e da sua substituição por uma perspetiva "mais complexa das relações entre motivação, comportamento e instituições” (Chang, 2001: 18).

Para captar o significado desta última afirmação basta considerar duas variáveis essenciais de toda a economia, salários e taxas de juro. Ambas "são, em larga medida, determinadas politicamente. Os salários não são apenas modificados pela legislação acerca do salário mínimo. São-no também pela regulação das atividades sindicais, dos padrões de trabalho, dos direitos sociais e, sobretudo, pelo controlo da imigração" (ibidem: 12).

Esta distinção essencial entre política e economia faz, assim, pouco sentido ao considerarmos o quadro em que assenta o funcionamento das 
sociedades contemporâneas. O Estado não é, portanto, o reduto da política (e das elaborações sociais) enquanto a economia não é apenas constituída pelo mercado, não sendo igualmente uma entidade despolitizada, objetivável num conjunto de relações "naturais" correspondentes à troca e às transações que a viabilizam. Por isso, o Estado não é necessariamente um obstáculo ao mercado, é sobretudo uma das entidades que o viabilizam.

Neste sentido, as experiências históricas de desenvolvimento, com relevo para as dos países hoje mais ricos, revelam a presença extensa de diferentes formas de intervencionismo, contrariando a narrativa liberal de que a intervenção deve ser mínima porque bastam as noções de que "o sistema de preços constitui um mecanismo eficiente de afetação de recursos" e de que "o desenvolvimento ocorre naturalmente desde que estejam criadas as condições propícias ao investimento privado” (Mamede, 2009: 179-180). Ao contrário, há questões de escalas de produção elevadas que são necessárias para possibilitarem "economias de escala estáticas" e que exigem investimentos iniciais elevados, assim como são precisos mercados alargados ou processos que tornem aquelas "economias de escala dinâmicas", por exemplo através de economias de aprendizagem, e da "superação das falhas de coordenação na produção" - tudo justifica a intervenção estatal (ibidem: 182-184).

\section{O leque complexo de papéis do Estado imerso na sociedade: base, ação e trajetória}

O uso social do Estado não se limita, pois, a uma noção contratualista abstrata, estabelecida por indivíduos autossuficientes que pretendem reservar para a sua ação um espaço despolitizado, a que se chame mercado ou economia. Exatamente porque o mercado é uma construção, isso implica a existência de uma densa complexidade institucional que o interliga geneticamente com o Estado. E não se trata apenas da função de superar as "falhas de mercado" que a teoria neoclássica do Estado lhe atribui. Mas o que também parece certo é que os Estados modernos das sociedades capitalistas desenvolvidas ou em desenvolvimento não têm de ser vistos apenas, como em certo sentido sugere Chang, como uma entidade estritamente institucional, isto é, definidora das relações políticas essenciais, designadamente daquelas que constroem e viabilizam o mercado. Em boa verdade, ele vê essencialmente o Estado como um interveniente na construção das motivações dos indivíduos: na boa linha institucionalista, ele "não vê estas motivações como dadas mas antes como sendo essencialmente moldadas pelas instituições que rodeiam os indivíduos" (Chang, 2001: 17). Por isso, o seu propósito, aliás muito útil, consiste em mostrar "como uma análise 'institucionalista' 
das relações entre motivação, comportamento e instituições pode melhorar o nosso pensamento acerca do papel do Estado" (ibidem). Mas há que convir que o Estado é mais do que isso, é uma entidade institucional plena, dotada de espessura material e, desse modo, presente não apenas no plano político ou da configuração dos comportamentos individuais mas também no plano económico e social. Não define apenas a viabilidade das relações em sociedade, é parte delas.

Por isso vou sugerir que, para se interpretar devidamente o processo e construção dos mercados, se distinga a ideia de construção política institucional (com que pretendo representar a proposta de Chang) da de instituição política material e relacional, assente numa rede densa de papéis desempenhados pelo Estado na economia e na sociedade. Com esta sugestão pretendo captar a relação entre dinâmicas sociais e consagrações institucionais, por um lado, e, por outro, pretendo sublinhar que as instituições, elas próprias, desempenham um papel material ativo, não sendo meras formas de consagração política do que a sociedade espontaneamente origina.

O papel do Estado na economia e na sociedade e o seu significado institucional têm, pois, uma forte densidade material e são um produto da evolução histórica. Mais ainda, esse papel resulta, na sua principal medida, de tensões sociais, cuja resolução, sob a forma de acordos ou compromissos, se torna necessária e, uma vez obtida, passa a constituir um novo patamar que serve de suporte a dinâmicas sociais subsequentes. Além disso, apesar de ser um produto das dinâmicas históricas, o papel do Estado constitui uma relação hierárquica. O Estado não é, assim, uma simples presença nas interações sociais ou contratuais. O Estado é, ao mesmo tempo, um configurador das dinâmicas coletivas e um definidor de uma determinada ordem relacional, através da legitimidade que obtém e do poder que o define.

$\mathrm{Na}$ verdade, o Estado moderno desenvolve um leque complexo de ações e, por isso, a compreensão do seu papel material, configurador das economias, não se alcança enfatizando apenas que os mercados são construções políticas institucionais, dependentes do desenho jurídico estatal. Os usos sociais do Estado neste tipo de sociedades demonstram a existência de uma rede densa de formas de ação. O Estado ordena e consagra padrões hierárquicos de organização coletiva (como decorre do que se disse atrás sobre economias de escala e de aprendizagem e coordenação na produção), define e redefine os domínios públicos e privados e isso exerce-se através de diversos papéis, que não se limitam à lei, à formulação regulamentar ou ao seu papel político. Exerce-se também através de políticas substantivas, quer as mais longamente consolidadas, com as que estruturam a prestação de serviços de educação, de saúde, de formas de ação social de incidência 
pessoal, quer as que desenvolvem formas de estruturação moderna das sociedades, nos domínios urbanos, da mobilidade, da ciência, do ordenamento e desenvolvimento dos territórios. Ora, os mercados, na dimensão e na forma que assumem, relacionam-se e dependem deste papel substantivo do Estado, e não apenas da sua função estritamente política. A este propósito, pode retomar-se aqui o diálogo com Chang e anotar a análise que, num plano distinto daquele em que anteriormente discuti, ele faz do papel das empresas públicas na correção das deficiências do mercado e na construção de relações de desenvolvimento no longo prazo, sobretudo em países menos desenvolvidos (Chang, 2007).

Embora seja certo que as funções de poder e domínio do Estado são historicamente dinâmicas e evolutivas, há, porventura, três aspetos que permitem observar a densidade das ações públicas, para além do domínio estritamente político em que há pouco se definiu a relação Estado/mercado. Em primeiro lugar, o Estado define e consolida infraestruturas coletivas do funcionamento social e da inovação. É esta, porventura, a base sobre a qual as sociedades, as economias e os mercados se desenvolvem. Para além disso, em segundo lugar, e num plano que já não é essencialmente de ordem material, o Estado influencia, através de princípios que promove (por exemplo, solução pública ou solução privada de problemas da sociedade), os padrões coletivos do desempenho económico e social. Isso indicia a presença ou a relação do Estado com a própria ação da sociedade e da economia. Finalmente, o Estado (mesmo nas situações históricas em que se pretendeu configurar como Estado mínimo) corporiza orientações estratégicas, quer dizer, ele é um elemento ativo da configuração de trajetórias. Em suma, o Estado pode ser encarado como um ator essencial da formação de uma determinada ordem relacional e o principal agente criador de externalidades na economia. Se este último papel lhe é geralmente reconhecido, parece também claro que o anterior não é menos importante, situando-se num espaço intermédio entre as suas funções materiais e as suas funções políticas.

A centralidade do Estado na economia é grande quando é grande o seu papel na estruturação dos comportamentos dos atores sociais e das relações que estes estabelecem. De facto, não será apenas o peso da despesa pública no PIB ou o conjunto dos meios económicos possuídos pelo Estado que servem de indicador da sua importância. Os papéis do Estado são também os de estabelecer contextos de ação, fixar significados, estabelecer consensos (Reis, 2001). Há, assim, uma contratualidade implícita nas relações entre o Estado e a economia. Mas uma contratualidade radicalmente diferente das que as visões liberais anteriormente criticadas pressupõem. É a este tipo de contratualidade que chamo ordem relacional. A demonstração 
deste papel do Estado não se encontra nas estatísticas nem resulta de uma dedução aritmética. Está diretamente ligada a uma interpretação das dinâmicas relacionais. Por exemplo, quando se trata de criar uma estrutura de direitos sociais (direitos sindicais, laborais, salariais, direitos reguladores da segurança social, da saúde) e de qualificar as gerações futuras (com papel preponderante para a educação e para a formação profissional), encontramos um papel de fomento exercido pelo Estado que serve de base aos processos de desenvolvimento. A própria estabilização das variáveis macroeconómicas, quando isso é necessário, é essencialmente um papel solitário do Estado, pois a regulação das relações monetárias externas, a condução da capacidade de troca, o desenvolvimento do crédito, o enquadramento da produção e do consumo e, até, a salvaguarda da capacidade produtiva, têm muitas vezes lugar na ausência de parceiros sociais fortes e, sobretudo, autónomos e construtivos.

O Estado é, assim, um criador de externalidades. ${ }^{8}$ A produção de capital fixo social, de infraestruturas modernizadoras, de qualificação geral da sociedade é um grande domínio de concretização material da função estatal. É compreensível que seja assim em fases e em circunstâncias em que há entraves aos processos de democratização social e política. Tanto os direitos sociais e a qualificação humana quanto a modernização infraestrutural exigiam esse capital fixo. No primeiro domínio estão as infraestruturas de educação, saúde, formação profissional. No segundo estão as estruturas de mobilidade, bem-estar urbano, bem-estar individual, assim como os contextos materiais de funcionamento das empresas. Pode imaginar-se como este papel do Estado foi decisivo.

O que torna as relações Estado/sociedade num problema essencialmente relacional é que, ao lado do papel "autónomo" do Estado, há também dinâmicas sociais difusas que exigem o envolvimento estatal. Esta relação entre evolução dinâmica relativamente difusa e estruturação formal parece-me central na compreensão da relação entre o Estado e sociedade. Foi J. K. Galbraith quem, em termos modernos, traçou de forma original os termos em que esta dialética opera. Em A sociedade da abundância, Galbraith (1963) discorre sobre os processos e sobre "os meios de alcançar primeiro e manter depois um certo equilíbrio no caudaloso fluxo de bens e serviços que, ano após ano, a nossa riqueza nos vai oferecendo". Referindo-se ao progresso e à evolução social enquanto processo difuso, dedica-se sobretudo a pensar

\footnotetext{
${ }^{8}$ Uma externalidade positiva, em economia, refere-se a uma criação de benefícios que transcende os agentes a ela diretamente ligados e que favorece o conjunto dos agentes sem que isso se manifeste através do sistema de preços.
} 
no "setor da produção privada". Mas não deixa de convir que, "ao mesmo tempo que isto se passa, manifestam-se, sem que seja preciso inventá-las, necessidades instantes de escolas, hospitais, demolição de bairros insalubres, desenvolvimento urbano, sanidade, parques, terrenos de jogo, policiamento e milhares de outras coisas" (ibidem: 261). A convicção central é que "entre os serviços públicos e a produção e utilização privada de bens e serviços existe determinada relação, a qual não pode descer aquém de um certo mínimo sem que surjam desordens sociais e fique comprometido o funcionamento normal da economia" (ibidem: 218).

No entanto, pode dizer-se que o contributo de Galbraith tem a finalidade de fixar os dois polos da dinâmica relacional. Por isso, ao contrário das perspetivas que atribuem ao indivíduo soberania plena, ${ }^{9} \mathrm{em} O$ novo Estado industrial, prefere "analisar um formidável aparelho de processos e de motivações que lhe modificam radicalmente o sentido" (1967: 264). Centra-se, para isso, na "tecnoestrutura" que rodeia e dirige a grande empresa, a cujas "necessidades e conveniências", aliás, "o mercado, em vez de ser o poder que dirige a economia, [se] acomoda progressivamente". Este "Estado industrial" é, como se vê, muito mais do que a instância política, é um complexo de relações densas entre a esfera pública e a privada. A dimensão e a substância da própria economia privada desligam-se radicalmente do indivíduo e da conceção normativa de mercado para assumir, ela mesma, uma natureza institucional. Tanto no processo de geração das possibilidades que originam estas circunstâncias como na consagração da sua ação subsequente, as fronteiras do espaço estatal e do espaço económico diluem-se e ganham porosidades.

\section{A rediscussão do problema perante uma crise fundamental}

O conjunto de considerações anterior redobra de significado perante a crise atual - uma crise que, dada a natureza da rutura entre domínios e agregados económicos, prefiro designar crise fundamental. De facto, não são só as noções teóricas e as ontologias do Estado e do mercado que merecem discussão e reflexão. O poderoso processo de reconfiguração das relações substantivas na economia não se limitou a dar aos mercados um papel desproporcionado. Mostrou como aí ocupa um lugar destacado a redefinição de certas categorias que são essenciais para a discussão da relação Estado/mercado. É, aliás, a própria noção de economia, de sistema económico, que carece de uma compreensão apurada. Foi sempre assim, mas não é desadequado dizer-se que isso se tornou mais relevante nas circunstâncias

\footnotetext{
${ }^{9}$ Neste contexto, Galbraith problematiza a ideia liberal da "soberania do consumidor".
} 
turbulentas que marcam o mundo, pelo menos desde que em 2008 se tornou clara uma situação de crise profunda. Interrogarmo-nos sobre o que constitui a economia e sobre as suas finalidades deverá conduzir-nos à ideia de que a economia é um sistema de provisão e uso de bens e serviços e destinado a desencadear processos de geração de bem-estar e de melhoria das capacidades humanas, tanto individuais como coletivas. Os mercados ou a economia não são, portanto, um jogo simples e livre (libertino) de afirmação de interesses, de interpretação de motivações ou de difusão errática de incentivos ou sanções. Quem centra a economia em lógicas individualistas, em relações competitivas de natureza interesseira ou egoísta, pode dar-se bem com definições muito estritas dos sistemas económicos e da própria ciência económica, quando esta se foca numa conceção maximizadora e normativa de racionalidade individual e na redução do conjunto dos mecanismos sociais de alocação de recursos e de coordenação económica a um único deles - o do jogo dos mercados.

São conhecidas as circunstâncias tumultuosas dos tempos atuais, decorrentes da financeirização da economia internacional: a entrega do financiamento e do crédito internacionais aos mercados liberalizados e à especulação desencadeou uma crise financeira e esta transformou-se rapidamente numa crise económica profunda e certamente prolongada, mal a turbulência se manifestou num sistema bancário desregrado. Em termos muito gerais, vale, no entanto, a pena relembrar que, de forma mais profunda, estivemos e estamos perante dois fenómenos incontornáveis. Um deles consistiu no facto de a função social do crédito e do financiamento se ter desconectado radicalmente da economia e dos objetivos de geração de riqueza e de promoção das capacidades individuais e coletivas, em favor de uma autonomização descontrolada da intermediação financeira e da especulação. O que devia ser instrumental tornou-se fonte das normas e assumiu capacidade de mando.

O segundo fenómeno - porventura o mais profundo - resultou da própria desconexão da economia relativamente à sociedade. A economia, definida da forma que há pouco se sugeriu, tem de ser concebida como uma realidade estreitamente articulada com a sociedade. Quer dizer, a economia não pode ser alheia ao conjunto plural de indivíduos e organizações e aos padrões culturais e institucionais que eles estabelecem, bem como aos compromissos e objetivos que resultam do conflito e dos acordos que as comunidades humanas vão gerando. Mas bem sabemos que esta relação se inverteu à medida que tendeu a prevalecer uma noção normativa e redutora da economia, em que esta se impõe à sociedade, em vez de com ela se relacionar positivamente. 
Este duplo processo de "desligamento" originou situações generalizadas de insustentabilidade, que agora não se limitam ao domínio financeiro, visto que dizem respeito aos próprios domínios económicos e sociais, para já não referir os ambientais. O que parece claro é que o quadro de circulação e disponibilização de capitais escapou quer a formas de regulação ajustadas, quer à presença prudente de um conjunto plural de mecanismos de alocação de recursos, com enorme fragilização da esfera pública. Pelo contrário, caminhou-se para uma solução única, totalizante e, seguramente, totalitária - a dos "mercados sem fim". Como João Rodrigues (2009: 57 ss.) indicou, a conversão do que Polanyi designou mercadorias fictícias (trabalho, natureza, terra e sistema monetário e financeiro) em simples mercadorias deve ser considerado como o processo mais profundo e substantivo de redefinição do quadro das relações económicas contemporâneas, pondo em causa a noção de economia que acima apontei e colocando numa crise fundamental as relações que tinham estabilizado o capitalismo, enquanto sistema de produção, ao longo das últimas seis décadas. O resultado mais evidente foi uma multiplicação de situações turbulentas, que desencadearam irracionalidades, fomentaram desigualdades, consolidaram periferias e reforçaram assimetrias. Como seria, aliás, lógico esperar-se, em vista da "desconstrução" social e económica a que comecei por aludir. Esta crise é, pois, o culminar destes processos e apresenta-se, por isso, como um poderoso fator de insustentabilidade social e política. No centro desse cenário estão os desequilíbrios profundos introduzidos pela financeirização da economia e pela imposição de lógicas e de comportamentos económicos alheios à produção, à criação de riqueza, à sua justa distribuição e ao que é mais essencial, a lógica inclusiva do desenvolvimento.

Por isso, quando se postula que a economia é um sistema social de provisão e uso que tem a criação de riqueza e a capacitação individual e coletiva como suas finalidades essenciais, então o quadro de problemas que se associa à economia há de ser diferente do que resulta da racionalidade financeira desregulada. E há de comportar quer uma interpretação adequada da globalidade dos fenómenos e dos processos que se nos apresentam, quer uma fina compreensão das relações Estado/mercado. É por isso, aliás, que parece claro que o problema da criação e distribuição de riqueza tem de regressar à primeira linha de prioridades da economia e da organização económica. É de estratégias de desenvolvimento que se trata. Estratégias significam opções voluntaristas, concertação de ações e de meios, presença central do interesse coletivo. Significam, pois, processos sociais complexos, compósitos, articulados, isto é, carentes de uma aproximação integral. 
Uma coisa parece certa. Nos dias de hoje, os puros mecanismos de mercado ("os mercados", essa entidade obscura e quase divina que ouvimos repetidamente ser invocada no dia a dia da discussão económica) não são hoje suficientes para relançar o crescimento e o bem-estar. Basta lembrar como se produziu, de forma radical, uma intensa apropriação especulativa e financeira da chamada lógica do mercado. $\mathrm{Ou}$, como bem lembra Mirowski (2010), a razão profunda pela qual os mercados têm uma tendência para um "vício inerente", o de se subverterem a si mesmos.

Quer isto dizer que me parece acertado colocar na agenda, sobretudo para economias periféricas, tópicos que ilustram bem a necessidade de refazermos muitas das inter-relações Estado/sociedade que já observámos e que postulámos como importantes para a discussão que aqui se propõe.

Parece-me claro que inquietações desta natureza sugerem preocupações semelhantes quanto ao conhecimento económico que se tem difundido e reproduzido de forma dominante nas últimas décadas. Sou um dos que acham que a teoria económica dominante foi um dos responsáveis ativos pela crise, designadamente pela teoria dos mercados que propalou. Quer isto dizer que a crise comporta um convite irrecusável ao regresso ao pluralismo das conceções económicas, o que certamente há de estar associado a visões prudentes sobre a organização económica e os mecanismos de que dispomos para promover a coordenação dos agentes.

É por isso que importa considerar que a economia, nesta aceção, não se resume às estruturas materiais e relacionais dos mercados, da produção e do consumo. As instituições, as culturas de decisão, os comportamentos, a governação e as atitudes relacionais dos atores económicos e sociais são também economia (Reis, 2010: 227-232). É necessário um paradigma económico mais amplo do que o que assenta na racionalidade do mercado para observar o modo como se estabelece a coordenação dos atores económicos, como se constrói a espessura do mercado, do Estado, da comunidade. O Estado "calibra" as debilidades do mercado e também lhe consagra o âmbito de atuação em que este é capaz de agir: por exemplo, vamos encontrar o Estado enquanto agente de delimitação da capacidade relacional do mercado, em termos geográficos, ao estabelecer um regime internacional assente na União Europeia.

\section{A compreensão do papel material do Estado exige uma teoria institucio- nalista do Estado e da sociedade}

A compreensão do papel do Estado exige certamente que pressuponhamos a natureza evolucionista do seu desempenho. O Estado liberal, o Estado social, o Estado neoliberal, o Estado neossocial são formas evolutivas cuja 
matriz e razão de ser encontramos nas tensões (nos conflitos e nos consensos) que determinam os vários planos das dinâmicas coletivas. Exige também, certamente, uma análise comparativa institucional, em que o pressuposto das "variedades de capitalismo" seja central. Ambas as aproximações facilitarão, por certo, uma clarificação da relação necessária entre a concretização histórica de cada forma de Estado e a condição de cada país. Central a uma perspetiva institucionalista está a ideia de que os indivíduos são capacitados pelas instituições através dos contextos, das referências e dos padrões que estas lhes possibilitam.

Se a natureza histórica do Estado e dos papéis que desempenha na economia e na sociedade não precisarão de ser especialmente realçados, já a perceção da ontologia estatal dependerá mais fortemente do que a visão evolucionista nos oferece. Suponho que é importante atender ao facto de ser notório o paralelismo entre os processos cumulativos de desenvolvimento material, por um lado, e a constituição do Estado como agente estruturador desses processos, por outro lado. Por exemplo, a configuração do Estado social não pode deixar de se considerar fortemente associada aos fenómenos mais intensos de transformação das sociedades capitalistas que seguem trajetórias dinâmicas. A industrialização, a salarização, a urbanização ou o desenvolvimento de mecanismos redistributivos sugeridos pelo aumento da capacidade coletiva para criar mais riqueza consolidaram lógicas de "progresso" inevitáveis e definiram padrões sociais não reversíveis. Poderia considerar-se que tudo isto assenta em mecanismos de natureza social ou económica distintos dos de natureza política e mais poderosos do que eles. Neste sentido, poderia também admitir-se que a natureza do Estado ou a sua qualificação como social, ou de bem-estar, ou providência, é empurrada pela própria evolução material e coletiva, isto é, pela dinâmica das estruturas que configuram a sociedade e as suas interações.

Mas parece também claro - e é isso que torna complexa a relação do Estado com a economia e a sociedade e revela a pluralidade dos fenómenos que a compõem - que tal evolução da vida material e das relações sociais carece radicalmente de ser consagrada, consolidada, "formalizada" institucionalmente. Ora, isso supõe um papel que só uma entidade estruturada, dotada de poder e de capacidade de legitimação, e relativamente autónoma, como o Estado, pode assegurar. É aí que a natureza evolucionista do Estado se revela como a instituição que valida, legitima, consagra e dá sentido cumulativo àquilo que a sociedade e a economia viabilizaram através das dinâmicas materiais e relacionais que lhes são próprias. As inter-relações e interdependência são, pois, poderosas. 
Uma análise interdisciplinar não pode deixar de dar uma atenção particular aos usos sociais do Estado, e não à sua condição transcendente. O seu papel na produção de normas e regras, a sua função legitimadora, o próprio facto de ser uma organização, isto é, um lugar de acumulação de saberes e competências, mostra-nos que o Estado define contextos de ação, formas de comportamento coletivo e de bem-estar individual, estabelece redes densas e complexas, produz impactos fortes em decisões não-estatais e na definição de objetivos sociais. De facto, o Estado é a-instituição-das-instituições e, por isso, é uma entidade profundamente material, relacional, interveniente em lógicas processuais cujo lugar não tem fronteiras exatamente delimitadas.

Como se afirmou logo no início, a perspetiva que enfatiza a natureza política autónoma, desligada da sociedade, do Estado parece pouco útil para as finalidades que aqui se prosseguem. De facto, o Estado é mais facilmente interpretável se considerarmos os usos sociais que ele serve e a profunda inter-relação com domínios que só de forma errada se podem considerar como autónomos. Viu-se anteriormente que a validação e consagração de formas evolutivas desencadeadas pela sociedade é um desses usos, especialmente relevante se admitirmos que estamos perante processos que representam uma condição progressista, tanto em termos materiais como sociais. A função de produção de regras e normas não é, assim, uma simples característica abstrata definidora do Estado. Pelo contrário, a relevância das instituições nas sociedades vê-se pelo seu papel na estruturação das interações sociais.

As regras e as normas, as regras implícitas e, sobretudo, as regras sociais mostram o papel institucional do Estado. Hodgson (2006: 2) encara as instituições "como sistemas de regras sociais estabelecidas e dominantes que estruturam as interações sociais", enquanto para North (2005: 1) as instituições são "restrições institucionais" que se "acumulam ao longo do tempo", de tal forma que "a cultura de uma sociedade é a estrutura cumulativa de regras e normas (crenças/valores) que herdamos do passado e que marcam o nosso presente e influenciam o nosso futuro".

A dimensão institucional ou a estrutura institucional apela, pois, para a compreensão de três aspetos decisivos: a acumulação de valores ao longo de processos longos, a sua consagração sob forma legitimada e legitimadora e a condição multiforme desses valores, de tal forma que eles assumem não apenas a característica de normas mas também de cultura. É neste contexto que a perceção do Estado colhe, com proveito, da conceitualização própria da noção de instituições, nos termos que acabo de propor.

A dimensão normativa que acabámos de observar consagra e institui valores, ideias, culturas - e um sistema institucional é, antes de tudo, isso 
mesmo. Por tal razão, tenho definido instituições como "consolidações coletivas de formas de compreender, agir e organizar as acções em sociedade" (Reis, 2009: 20). Numa aceção larga e dinâmica, certas instituições devem também ser vistas como entidades dotadas de espessura própria, com pesos e papéis substantivos na sociedade, isto é, como sujeitos de ação. Ora, o Estado, para além do que consolida e consagra sob a forma de instituição legitimadora, é também um lugar de acumulação coletiva, de acumulação de saberes e de competências, e é isso que o delimita e define como organização. As dimensões técnicas e organizacionais tornam-se especialmente relevantes em funções como as de administração, de regulação, de planeamento e de provisão. O aparelho técnico-estatal mostra o que, no Estado, existe para além da sua natureza política. Essas funções relacionam-se com processos de intervenção na organização coletiva.

Um dos aspetos da dinâmica histórica que melhor poderá exemplificar a natureza institucional da evolução económica e social e, portanto, a relação Estado/economia, é a emergência da sociedade salarial. Pode admitir-se que a questão essencial consiste na passagem do salário de categoria imersa nas relações de dependência pessoal à categoria de variável "económica". Se neste caso estaríamos perante mercados de trabalho iniciais como contextos "privados" altamente assimétricos, com a sociedade industrial a natureza de tal variável muda radicalmente. O salário deixa de poder ser visto como uma simples retribuição da cedência de trabalho para ter de ser encarado como uma relação central, tanto económica como política. A dupla condição do salário - simultaneamente custo e rendimento - associa-se rapidamente a outra dimensão, a de salário direto e a de salário indireto. O facto de ser um custo mostra que vai haver uma relação reforçada entre salário e produtividade. Ora, esta última liga-se diretamente a condições microeconómicas e organizacionais próprias da empresa, mas liga-se também, igualmente de forma direta, a capacidades do trabalhador que não lhe são dadas pelo empregador (educação, saúde, mobilidade, inserção numa rede de relações sociais), dependendo antes de decisões públicas prévias e da garantia de formas de provisão que possibilitam acessos coletivos. Para além desta relação avaliável em termos microeconómicos, a capacidade de suportar determinados níveis de custo por parte das empresas depende também dos contextos de valorização da sua própria produção de bens ou serviços. Ora, a isso associam-se as externalidades positivas de que possam ou não beneficiar - externalidades de características infraestruturais ou externalidades de informação, de conhecimento ou simplesmente contextuais.

É, no entanto, o facto de o salário também ser um rendimento, com que a maioria dos cidadãos forma a sua procura e assegura a inserção no quadro 
social, que enfatiza a natureza económica, pública e coletiva da relação que o origina. Os seus impactos e influências passam a ser macroeconómicos e macrossociais e, evidentemente, políticos. Desde logo porque é o conjunto das dinâmicas globais de uma sociedade, desde as de crescimento às de bem-estar, que lhe está associado. Isso mesmo tem a ver com o facto de, em sociedades deste tipo, não bastar que a relação salarial se limite ao salário direto, quer dizer, à relação monetária imediata que se estabelece entre empregador e trabalhador. Para além de esta ter uma dimensão contratual que envolve várias outras dimensões em matéria de direitos e de obrigações (que em si mesmo já definem níveis de salário indireto), são as políticas públicas e as formas de intervenção do Estado no rendimento dos cidadãos, estabelecidas no pressuposto de que o mercado do trabalho é um mecanismo poderoso de inclusão social, que finalmente definem esse salário indireto.

Por todo este conjunto de razões, a relação salarial passa, assim, de uma relação económica de produção privada para uma relação social de natureza pública, fundadora, aliás, de uma fase nova na história, marcada não apenas pela industrialização e pela salarização mas também pela urbanização, pelo desenvolvimento do conhecimento e pelo lugar essencial da organização coletiva.

As constituições económicas dos países industrializados e as democracias laborais que aí se desenvolveram até à súbita deflação salarial originada pela crise iniciada em 2008 são expressões concretas do que se acaba de dizer. Se considerarmos a relação entre salário direto e salário indireto e todas as formas de políticas sociais associadas à condição dos trabalhadores, pode perguntar-se: quanto é que, na retribuição dos assalariados, é política pública? A passagem do salário de simples relação individual às convenções parciais de tipo setorial e, depois, às normas salariais gerais e aos padrões laborais mínimos mostra a presença de processos de natureza variada, mas interligados.

\section{Conclusão: os exercícios institucionalistas e relacionais sobre Estado e mercado (e a turbulência do mundo)}

O papel do Estado nas sociedades contemporâneas, apesar das diferenças que possa revelar consoante os contextos nacionais, é o resultado de um longo processo relacional. Nesse processo intervêm fenómenos sociais relevantes e problemas essenciais de organização coletiva. E intervém, igualmente, o efeito produzido pelas próprias soluções institucionais que fixam e delimitam o lugar do Estado nas sociedades. A natureza política do Estado e a consolidação institucional que ele representa estão intimamente vinculadas à lógica de conflito e compromisso que os fenómenos e as dinâmicas sociais comportam. 
Ambas as matérias - tanto a fenomenologia relacional como a consagração institucional de soluções e formas de intervenção - indiciam questões que são intrinsecamente processuais e históricas. Regresse-se aos exemplos já anteriormente dados, acerca da urbanização e da industrialização. Estamos perante circunstâncias coletivas de construção dos processos sociais que exprimem tanto dimensões da vida material quanto da configuração institucional, neste caso de tipo estatal, que elas desencadeiam. O lugar dos processos coletivos na organização social pode ser reconstruído a partir de pontos com origens muito diversas. Importa, no entanto, interpretar devidamente as circunstâncias com que nos deparamos no mundo real. As soluções redutoras conduzem certamente a problemas de sustentabilidade disciplinar, como é hoje em dia bem ilustrado pela economia que, ao reduzir-se a uma disciplina dos mercados, minou profundamente a sua condição científica e a sua capacidade para interpretar a evolução social, tendo também sido responsável por uma "colonização" do espaço público através de ideias controversas. Daí a utilidade de uma visão "indisciplinar" que se aproxime da globalidade e da complexidade dos fenómenos e dos processos sociais.

\section{Referências bibliográficas}

Buchanan, James (1986), Liberty, Market and State: Political Economy in the 1980s. Brighton: Wheatsheaf Books.

Buchanan, James (1991), Constitutional Economics. Oxford, Cambridge: Basil Blackwell. Chang, Ha-Joon (2001), "Breaking the Mould - An Institutionalist Political Economy Alternative to the Neo-Liberal Theory of the Market and the State, Social Policy and Development Programme", Paper 6. New York: United Nations, Research Institute for Social Development.

Chang, Ha-Joon (2007), State-Owned Enterprise Reform, Policy Notes. New York: United Nations, Department for Economic and Social Affairs, National Development Strategies.

Chang, Ha-Joon; Nolan, Peter (1995), "Europe versus Asia - Contrasting Paths to the Reform of Centrally Planned Systems of Political Economy", in Ha-Joon Chang; Peter Nolan (orgs.), The Transformation of the Communist Economies - Against the Mainstream. London/Basingstoke: Macmillan.

Furubotn, Eirik G.; Richeter, Rudolf (2001), Institutions and Economic Theory: The Contribution of the New Institutional Economics. Ann Arbor: The University of Michigan Press.

Galbraith, John Kenneth (1963), A sociedade da abundância. Lisboa: Sá da Costa.

Galbraith, John Kenneth (1967), O novo Estado industrial. Lisboa: Publicações Dom Quixote. 
Hall, Peter; Soskice, David (2001), Varieties of Capitalism. The Institutional Foundations of Comparative Advantage. Oxford: Oxford University Press.

Hirschman, Albert (1991), The Rhetoric of Reaction: Perversity, Futility, Jeopardy. Cambridge: The Belknap Press of Harvard University Press.

Hodgson, Geoffrey (2006), “What Are Institutions?”, Journal of Economic Issues, XL(1), 1-25. Hollingsworth, J. Rogers; Boyer , Robert (1997), "Coordination of Economic Actors and Social Systems of Production”, in J. Rogers Hollingsworth; Robert Boyer (orgs.), Contemporary Capitalism: The Embeddedness of Institutions. New York/Cambridge: Cambridge University Press, 1-47.

Jackson, Gregory; Deeg, Richard (2006), "How Many Varieties of Capitalism? Comparing the Comparative Institutional Analyses of Capitalist Diversity”, Discussion Paper 06/02, Max Plank Institute for the Study of Societies.

Mamede, Ricardo Pais (2009), "Os desafios do desenvolvimento económico e o papel das políticas públicas”, in Renato Miguel Carmo; João Rodrigues (coords.), Onde pára o Estado. Lisboa: Edições Nelson de Matos.

Mirowsky, Philip (2010), "Inherent Vice: Minsky, Markomata, and the Tendency of Markets to Undermine Themselves”, Journal of Institutional Economics, 6(4), 415-443.

Neves, Vítor (2004), "Situational Analysis Beyond 'Single-exit' Modelling”, Cambridge Journal of Economics, 28(6), 921-936.

North, Douglass (2005), Understanding the Process of Economic Change. Princeton e Oxford: Princeton University Press.

Pereira, Paulo Trigo (1997), "A teoria da escolha pública (public choice): uma abordagem neoliberal?”, Análise Social, 141, 419-442.

Polanyi, Karl (1957), The Great Transformation. Boston: Beacon Press.

Reis, José (2001), “A globalização como metáfora da perplexidade? Os processos geoeconómicos e o 'simples' funcionamento dos sistemas complexos”, in Boaventura de Sousa Santos (org.), Globalização: fatalidade ou utopia? Porto: Edições Afrontamento, 109-134.

Reis, José (2009), Ensaios de economia impura. Coimbra: Almedina/CES.

Reis, José (2010), “Um ciência indisciplinar: a cidade dos economistas”, in Vítor Neves; José Castro Caldas (orgs.), A economia sem muros. Coimbra, Almedina/CES.

Reis, José (2012), “Um exercício interdisciplinar: identificar o lugar do Estado na economia”, in Celia Lessa Kerstenetzky; Vítor Neves (orgs.), Economia e interdisciplinaridade(s). Coimbra, Almedina/CES.

Reis, José; Nunes „oão Arriscado (1993), “Albert O. Hirschman: a propósito de The Rhetoric of Reaction", Notas Económicas - Revista da Faculdade de Economia da Universidade de Coimbra, 1, 108-112.

Rodrigues, João (2009), “Onde pára o mercado: movimentos e contramovimentos nas políticas públicas”, in Renato Miguel Carmo; João Rodrigues, Onde pára o Estado. Lisboa: Edições Nelson de Matos. 
34 | José Reis

Rodrik, Dani (2008), "Second-Best Institutions”, American Economic Review, American Economic Association, 98(2), 100-104.

Smith, Adam (1999), Teoria dos sentimentos morais. São Paulo: Martins Fontes [ed. orig.: 1759].

Stiglitz, Joseph (1999), "Whither Reform? Ten Years of the Transition”, Annual Bank Conference on Development Economics, Washington. 